\title{
OS DISCURSOS DE CRIANÇAS SOBRE AS QUESTÕES DE GÊNERO NO TRABALHO DOCENTE E NO MAGISTÉRIO
}

\author{
Tatiana do Socorro Corrêa Pacheco ${ }^{1}$
}

\section{Introdução}

Este estudo apresenta alguns resultados da pesquisa realizada no Mestrado em Educação (UFPA/2008), que investigou os significados e sentidos dos discursos de um grupo de crianças do $4^{\circ}$ ano do ensino fundamental sobre a profissão e os gêneros na docência. A pesquisa teve o intuito de discutir os desdobramentos das questões de gênero na prática docente do homem professor e da mulher professora que se apresentam nos discursos de crianças, bem como de analisar por meio dos discursos os significados e sentidos atribuídos pelas crianças à profissão e a docência de professores/as das séries iniciais do ensino fundamental. A centralidade atribuída aos discursos das crianças se fez necessária, por serem estas que vivenciam diariamente o trabalho docente exercido por professores/as. Apreendida e considerada como sujeito sócio-histórico, que vive a sua história e dá significado às suas ações, a criança foi neste percurso analítico vista como um ator social

O encontro com o tema ocorreu no ano de 2005, período em que atuei como professora do $2^{\circ}$ ano do ensino fundamental numa escola municipal localizada no município de Ananindeua-Estado do Pará, onde encontravam-se em exercício do $1^{\circ}$ ao $5^{\circ}$ ano, no período em a investigação foi realizada, 08 professores homens e 19 professoras, considerando que $81,3 \%$ dos docentes da Educação Básica no Brasil são mulheres e apenas 18,7\% são homens ${ }^{2}$. Isso me fez lembrar que aquela situação não era de certa forma considerada comum, em função da história de feminização que o magistério possui, principalmente, na educação infantil e nas séries iniciais do ensino fundamental. Percebi que a criança estava situada num espaço de produção de identidades, que é a escola, e essa instituição ficou marcada historicamente como um espaço de trabalho para as mulheres.

A opção pela recolha das vozes infantis, coloca a criança numa posição ativa na pesquisa e faz considerar que em seu desenvolvimento questões de raça, gênero e classe estão presentes e as constituem. Essa opção também contribui na ruptura com conceitos fechados de infância, que não valorizam as suas especificidades sócio-culturais. Considerar a criança como um sujeito que se constrói nas suas relações com o mundo é percebê-la como ser histórico e social, para tanto, os discursos se apresentam como um meio de investigar e analisar os significados que estas produzem sobre as suas diversas experiências culturais. Como diz Bakhtin (2003), o homem social é o objeto real da investigação científica, que fala, que se exprime pela palavra. É assim que a investigação se torna diálogo, pois, é pela palavra que tentamos interpretar os significados e sentidos construídos socialmente, que podemos captar pontos de vistas, vozes sociais.

Os/As professores/as, ao se relacionarem com os/as seus/as alunos/as, e estes ao se relacionarem com seus/suas professores/as, põem suas crenças, verdades e valores como mediadores do processo de interação verbal. Nesse momento, as concepções de mundo emergem no fluxo dessas interações, revelando imagens, perspectivas, construindo conceitos, desconstruindo valores, ou seja, movimentam um jogo interacional em que as ideologias, as relações de poder são materializadas a partir das representações que possuem sobre determinada realidade.

\footnotetext{
${ }^{1}$ Professora da Universidade Federal Rural da Amazônia (UFRA). E-mail: tatianacpacheco@gmail.com.

${ }^{2}$ Pesquisa realizada pela UNESCO/2004, com o título: O perfil dos professores brasileiros: o que fazem, o que pensam, o que almejam.
} 
É, portanto, pela produção discursiva, que podemos perceber os preconceitos, as ideologias, que contribuem para a permanência das desigualdades de gênero. O ser masculino e o ser feminino são construtos sociais passíveis de captação por meio do discurso, pois, para Bakhtin (2003), é a partir deste que, nos definimos com relação ao outro e com relação à coletividade. A palavra é, também, determinada pelo grupo social a que o sujeito pertence e pelo seu contexto histórico. Assim, os valores, idéias, sobre as coisas que se encontram em circulação no meio social vão a partir das interações verbais realizadas sendo incorporadas, elaboradas e reelaboradas pelos sujeitos, e estes, a partir dessas experiências vão construindo os seus sentidos sobre o mundo, que podem estar marcados por preconceitos e ideologias.

O eu, para Bakhtin (2003), que é materializado pela palavra, é completamente formado pelo outro, pela família, pela escola, ou seja, pelo grupo social ao qual pertence, pelas interações realizadas com o seu meio social. A voz do sujeito, a voz do outro pressupõe um nós. A palavra, nesse sentido, não é só instrumento de comunicação, de mediação das relações do homem com o mundo, a palavra expressa o envolvimento deste com o mundo, a sua formação cultural.

Dessa forma, os discursos são valorizados e vistos como reveladores das compreensões e concepções sobre os gêneros na docência, e que podem evidenciar o contexto social, cultural e histórico destes profissionais. As vozes infantis são tomadas como essenciais para entender a concepção da criança sobre o magistério e sobre professores/as, bem como para refletirmos sobre a maneira de se pensar a profissão nas diferentes vozes sociais, ou seja, nos vários discursos criados sobre os gêneros, e que reforçam as desigualdades, os papéis, as funções, mediante as diversas ideias que veiculam sobre o ser masculino e o ser feminino em nossa cultura.

A escolha dos sujeitos participantes da pesquisa e os arranjos metodológicos acompanharam o pensamento Bakhtiniano e as especificidades dos sujeitos infantis. Brait (2003) lembra-nos que Bakhtin fala da importância do contexto extra-verbal que envolve o discurso e que é composto de 03 fatores: "1 - A extensão espacial comum aos interlocutores [...]; 2 - O conhecimento e a situação comum existente entre os interlocutores; 3 - A avaliação comum dessa situação" (BRAIT, 2003, p. 19).

Considerando tais fatores as crianças entre as idades de 09 a 11 anos foram escolhidas pelas experiências que possuíam com a docência exercida por ambos os gêneros, no mesmo espaço escolar e com o mesmo tempo de experiência (03 anos), o que possibilitou que os sujeitos infantis pudessem falar das suas experiências com professores e professoras, dentro do espaço que lhes é comum - a escola.

Os instrumentos utilizados na coleta dos dados foram entrevista coletiva semi-estruturada e o uso de duas imagens fotográficas adotadas como iniciadoras do diálogo com as crianças. A entrevista coletiva garantiu os diálogos, possibilitou uma interação mais rica, compartilhada, em que os sujeitos não se limitaram em responder as perguntas, mas puderam divergir, concordar, enfim, um espaço para a réplica ao discordarem ou concordarem entre si. As crianças participaram das entrevistas como sujeitos ativos, compreendendo o diálogo como algo mais amplo, nos termos de Bakhtin (2003), como um processo ativo e responsivo, de troca, de curiosidade em saber o que os/as colegas pensavam acerca do assunto.

A análise dos dados está fundamentada na perspectiva sócio-histórica e nas teorizações de Bakhtin (2003) sobre o discurso, pela importância que este autor atribui em se considerar as dimensões dialógicas e ideológicas na produção dos significados e sentidos presentes no discurso e que são historicamente determinados. 


\section{Os discursos de crianças sobre as questões de gênero no trabalho docente e no magistério}

Ouvir as crianças revelou muito sobre a docência de professores e professoras e de suas relações com estes profissionais. Considerando que gênero é uma categoria teórica em que se buscam os significados, e também as construções simbólicas sobre as diferenças sexuais, as análises se debruçaram nas formas como essas diferenças são (re)apresentadas pelas crianças, discutindo os seus desdobramentos na educação.

Foi a partir do corpus da pesquisa, ou seja, do conjunto dos enunciados, que destacamos 03 eixos-temáticos que evidenciam nos discursos das crianças significados e sentidos da profissão e da docência.

\subsection{Os vínculos históricos e culturais da profissão com a maternidade.}

Os discursos das crianças revelam uma construção cultural sobre a profissão em que o sexo do profissional que exerce a docência foi fundamental para as crianças definirem a profissão.

Ao serem questionadas sobre os motivos da existência de mais professoras na docência, as crianças apresentaram alguns significados em seus discursos que foram destacados abaixo:
Menina: Porque a mulher tem mais assim... cabeça pros alunos
Menina: É a mulher tem
Assim, porque tem algumas professoras que já é mãe, aí tem cabeça né? Pra dar aula pro seu filho pra sua filha.
Menino: Porque elas precisam arrumar emprego, pra poder ganhar o cheque da escola pra pagar as contas.
Menino: Porque elas precisam trabalhar pra sustentar a casa
Menina: Porque elas precisam de emprego, e elas pedem, e elas andam pra ganhar o cheque da escola.

O discurso da menina que justifica a presença de maior número de mulheres na docência pelo fato de "terem cabeça por serem mães", coloca a maternidade como um tipo de preparação para o trabalho docente. Esta criança compreende que a maternidade dá à professora uma certa habilidade para o trabalho docente. Para esta criança, a experiência materna possibilita o exercício da docência de forma mais adequada.

Seu discurso evidencia um significado de docência ligado a maternidade. A criança direciona para o trabalho docente as suas experiências com mulheres adultas como mães, não separando a atuação docente da prática de maternagem ${ }^{3}$. Neste sentido é possível afirmar que os referenciais que possui para falar da profissão é também o espaço doméstico, o vínculo e as relações afetivas que estabelece com a mãe. Neste aspecto Bakhtin (2003) nos diz que:

As influências extratextuais têm um significado particularmente importante nas etapas primárias de evolução do homem. Tais influências estão plasmadas nas palavras (ou em outros signos), e essas palavras são palavras de outras pessoas, antes de tudo palavras da mãe (BAKHTIN, 2003, p. 402).

\footnotetext{
${ }^{3}$ O termo maternagem nos estudos de gênero tem sido utilizado segundo Carvalho (1998), para enfatizar as dimensões culturais e históricas da criação de filhos/as em contraposição à dimensão biológica da maternidade.
} 
É neste processo de troca e de interação dialógica, que os discursos alheios são reelaborados, em que as vozes do outro são assimiladas, absorvidas tornando-se próprias do sujeito e com um sentido singular. Por isso, as mulheres parecem mais adequadas segundo a criança, para a atividade docente, pelo seu lado maternal, e este, o homem culturalmente não possui, por ser um aspecto socialmente definido como feminino A maternidade é valorizada, pois prepara as mulheres a serem professoras. Neste sentido, Carvalho enfatiza que a feminização do magistério não se refere apenas à entrada de mulheres para exercer a docência:

[...] mas, do lado da mudança na composição sexual da ocupação, também um processo de deslocamento de significados - de escola, ocupação, ensino, mulher, feminilidade, maternidade, masculinidade, criança - que resultou na contigüidade observada hoje entre as representações de mulher, mãe e professora. (CARVALHO, 1999a, p. 37).

O questionamento da identidade relacional de mãe-professora emitida pela menina se faz necessário em função de reforçar características instituídas, que historicamente atribuiu à mulher que é mãe um papel pedagógico que reforçou ideologias e estereótipos criados ao trabalho docente por ter sido visto como uma extensão das habilidades maternais. Esta criança se tornou sujeito deste discurso em que os sentidos atribuídos à mulher como mãe são apropriados por ela e associados à docência. A veiculação da ideologia da maternidade naturalizou características que são consideradas femininas estendendo-as à atividades que foram se delineando historicamente como extensão daquelas realizadas no lar, resultando num processo de articulação da maternidade à docência.

A construção destes significados sociais e históricos que associavam os sujeitos a determinados tipos de atividades como as maternais e de cuidados às mulheres, se expandiram a espaços de trabalho como as escolas, por serem vistas como uma extensão da maternidade. Foi com base nestes significados que a docência no Brasil no século XIX abriu o espaço de atuação para as mulheres, resultando na feminização do magistério no século XX. A ocupação do espaço educativo pelas mulheres tinha nos discursos ideológicos a sua força e justificativa "[...] a educação das crianças era um dos caminhos profissionais mais "adequados" para as mulheres (CHAMON, 2005, p. 52).

Os discursos ideológicos que a partir do final do século XIX e início do século XX defendiam a presenças das mulheres em sala de aula tinham o interesse pela preservação dos valores morais, guiados pelos preceitos positivistas de amor a Pátria e a família e viu na mulher uma característica moralizadora. Pelo seu poder civilizador ela resguardaria os bons costumes e contribuiria no controle dos sujeitos, favorecendo-lhe a possibilidade de exercer a profissão docente.

Os enunciados discursivos da criança reforçam o papel tradicional atribuído ao magistério como campo de atuação feminino. Estes discursos, segundo Bakhtin (2004), fazem parte dos sistemas ideológicos já constituídos e veiculam nos diversos espaços de circulação das crianças como a casa, a escola, influenciando nas suas formas de compreensão do mundo.

Carvalho (1996) afirma a partir de análises feitas do trabalho docente feminino que, o trabalho doméstico, não somente contribui na definição de atividades que são tidas como femininas, mas estão presentes na vida da maioria das mulheres. Esta autora constatou que:

[...] as falas e atitudes das educadoras, a maneira como enxergavam o trabalho docente, como organizavam o tempo e o espaço, assim como as relações que estabeleciam com as crianças e com as mães das crianças tinham como referencial a vida no lar, o trabalho doméstico, a maternagem, a socialização recebida para a vida doméstica. (CARVALHO, 1996, p. 78). 
Esta afirmação nos faz lembrar que Sarmento (2005), ao enfatizar a criança como ator social e a sua consideração como tal, deve-se estar atento as relações intergeracionais e intrageracionais que este sujeito estabelece, ou seja, os aspectos simbólicos que permeiam a cultura infantil são construídos por meio das relações com outros grupos como os adultos. Neste processo de relações muitas construções ideológicas permanecem veiculando por meio de discursos e práticas que reforçam tais construções. É neste sentido que podemos afirmar que a menina a partir das relações de gênero vivenciadas se utiliza da maternidade como referência principal para definir a docência feminina. O seu discurso é resultado das interações com os adultos no seu contexto de vivência social.

É importante salientar que nestas construções sociais que associam a docência a maternidade, o que deve ser questionado é a negatividade que se construiu historicamente para aquilo que Carvalho (1996) denomina de habilidades adquiridas pelas mulheres no seu processo de socialização. A autora também afirma que caberia aos estudos do trabalho docente deixar de tomar as características maternais e domésticas das professoras de forma pejorativa, como incompetência técnica, e passar a reconhecê-las como qualificações, que podem ou não se fazer presente em suas práticas em sala de aula e nas suas relações com os/as alunos/as.

O trabalho, atividade destacada pelas crianças, aparece nos discursos como algo que supera as questões de gênero, há mais mulheres na docência por uma necessidade de trabalho, de ganhar dinheiro para sustentar a casa e pagar as contas. As crianças em alguns destes discursos, não vêem o trabalho docente como exclusividade de um sexo, o trabalho é visto como necessário à sobrevivência independente de papéis ou atividades desenvolvida. As crianças revelam muito mais do que as questões de gênero pressupõem, revelam sobre o contexto em que estão inseridas, do significado social e econômico do trabalho.

\subsection{Os múltiplos sentidos na docência masculina}

No segundo eixo-temático de análise, podemos evidenciar outros sentidos atribuídos pelas crianças sobre os gêneros na docência. Estas, ao definirem o professor homem, nos apresentam outras formas de masculinidade, de exercício da docência e de relações com os/as alunos/as.

Menino: Eu gosto mais de professor porque quando eu fui estudar na $2^{\mathrm{a}}$ série ele falou assim: - Quem quiser ir ao banheiro vai. Aí depois ele ficou fazendo brincadeira com a gente.

Menina: Ele é legal, ele brinca com a gente, ele é gentil, ele não mente pra gente.

Menina: Ele chega dá boa tarde, a gente dá boa tarde pra ele, aí ele vai na mesa pra ver quem ta fazendo o dever. Pega na nossa cabeça.

Menino: Ele é legal.

Menino: Ah! Eu vejo ele alegre passando o dever, aí ele vai na mesa pra ver quem ta fazendo direito.

Menina: Tem, tem vezes que quando a nossa conta é de matemática; só um negócio que a gente não tava entendendo em matemática, ele ensinou pra gente. Ele ia na mesa de cada um pra ver qual é que tava certa. Aí quando tava errado ele falava: - Tá errado! Mas quando a gente vai pra nossa casa, aí a gente dá um beijo nele e ele também dá na gente.

Os discursos acima reafirmam as ideias de Connell (1995), ao retratar os gêneros como um campo complexo, que não se limita a binarismos ou polaridades, ou ao enquadramento dos sujeitos em modelos predeterminados. As crianças apresentam novos significados sociais para 
a docência masculina, a prática do professor está produzindo novos sentidos para as crianças, novas formas de se olhar para a docência que se distanciam das que foram convencionalmente construídas para homens e mulheres. Estas novas significações indicam que a educação deve ir além dos estereótipos, das concepções que enquadram os sujeitos em modelos fixos, deve dar espaço para o múltiplo, para reflexões sobre os diversos modos de vivência social dos sujeitos, evidenciar as descontinuidades, os indícios de rupturas com os papéis que foram historicamente atribuídos para homens e mulheres.

O gênero é relacional e por ser relacional, é formado nas interações sociais que estabelecemos com o outro, portanto, podem construir novos significados sociais, por meio de novas formas de relações e de novas práticas que envolvem homens e mulheres, como nos diz Connell (1995, p. 189): “[...] se o gênero é um produto histórico, então ele está aberto à mudança histórica”.

Para Bakhtin (2003), toda vivência está direcionada para um sentido, e com base neste pressuposto os sentidos emitidos pelas crianças sobre o professor se voltam para a prática deste profissional, ao que essa representa para os/as alunos/as. O que permeia os sentidos dos discursos destas crianças sobre o professor, são os vínculos afetivos e emocionais que estão presentes nas interações que ocorrem na sala de aula. Parece que quanto mais afetivas forem as relações, as hierarquias são menos enfatizadas, diminuem o seu significado. $\mathrm{O}$ controle, a autoridade e a vigilância formas históricas presentes na relação adulto-criança nas instituições escolares são menos evidenciadas.

É importante enfatizar o quanto o afeto foi historicamente concebido como algo que deveria estar distante nas relações entre professores/as e alunos/as, por estar relacionado a figura feminina e por não reforçar os aspectos técnicos e científicos do trabalho docente.

Em Bakhtin (2004), o sentido é apreendido como o conteúdo da experiência, como a interpretação valorativa desta. Esse autor considera que nos discursos dos sujeitos sobre dada realidade relacionam-se contextos (amplos e específicos), valores e experiências em que o eu e o nós se cruzam para lhe dar uma definição, um sentido. Portanto, os valores sociais que permeiam os sentidos das práticas de professores e professoras para as crianças, tem como base a afetividade, a permissividade, a brincadeira, a atenção. Estes aspectos que as crianças apresentam como importantes para o trabalho docente, são cruzadas com as identidades de gênero dos/as professores/as, com o tipo de relações que se estabelecem na sala de aula, com as especificidades do pensamento infantil, e com as diferentes interações vivenciadas pelos sujeitos infantis com homens e mulheres nos diversos espaços sociais, influenciando nos significados que estes atribuem às suas experiências.

\subsection{O exercício da docência e as relações afetivas.}

As crianças falaram de aspectos que são pouco reconhecidos como importantes para o trabalho docente, aspectos estes que estão vinculados às dimensões afetivas presentes neste tipo de atividade profissional e que para as crianças são importantes para um boa relação em sala de aula. Os sentidos da docência para as crianças foram apresentados com os seguintes discursos:

Menina: Mas professoras são todas iguais, porque as professoras brincam e os professores não. Só o professor de arte que brinca.

Menina: Às vezes o professor não deixa a gente ir pro recreio, quando a gente não tá fazendo que não termina.

Menina: Essa professora já é diferente, ela deixa a gente ir ao banheiro.

Menino: O professor só deixava quando chegava o recreio aí ele deixava. Menina: Porque ela deixa a gente ir pro recreio quando a gente não termina o dever 


\section{Menina: $E$ porque ela deixa a gente brincar. \\ Menina: Ah! Porque ele brinca com a gente, ele ensina mais, é mais legal. Menina: Tem uma diferença sim, por exemplo: ela é mais legal brincalhona com a gente. $O$ professor ele só explicava uma vez e não explicava mais. \\ Menina: É algumas coisas muda um pouco: brincar, escrever no quadro. Aí quando a gente pede pro professor algumas coisas aí ele não brinca. \\ Menina: Mas do que a gente gosta mesmo é do professor legal brincalhão como o professor de Arte.}

As crianças na maior parte destes enunciados discursivos colocam a brincadeira no centro das suas significações, permissividade e consentimento, também, fazem parte do sentido da docência. Uma visão do ensino baseada na generosidade e nos seus interesses e necessidades.

Ser legal para as crianças é permitir a brincadeira e participar delas, é ir ao banheiro, ao recreio, ter paciência ao ensinar. Essas características as crianças relacionam mais ao fazer docente feminino. As crianças estabelecem uma relação brincar-ensino-afetividade, os seus desejos permeiam esta compreensão. Em suas produções discursivas o afeto tem um poder valorativo significativo, é um aspecto importante no exercício da docência.

Estes sujeitos sugerem um tipo de relação em sala de aula e de prática pedagógica, colocando aspectos como a paciência, a brincadeira e o afeto como importantes no cotidiano de sala de aula. O cuidado, o vínculo afetivo, a brincadeira, possuem um sentido central para as crianças, são vistos como estimulantes para a sua aprendizagem. Os seus discursos indicam que os vínculos emocionais podem ser ferramentas importantes para um bom trabalho docente.

Uma questão interessante apresentada por Carvalho (1999b) a respeito do trabalho docente, se refere à dimensão relacional deste tipo de trabalho, que implica em exigências emocionais que estão ligadas ao relacionamento com crianças e que neste sentido independem do sexo do docente.

\footnotetext{
Dois tipos de abordagens têm predominado na literatura pedagógica brasileira ao tentar explicar esse relacionamento intensamente afetivo estabelecido entre professores/as primários/as e seus alunos. Ambas partem da constatação de que se trata de uma maioria de docentes do sexo feminino e tendem atribuir essa marca a características da feminilidade, sem distinguir teoricamente o plano das prescrições do plano das identidades individuais de gênero, confundindo assim características do trabalho docente com sexo do professor ou professora. (CARVALHO,1999b, p. 23)
}

Para Carvalho (1999b) temas como o afeto e os vínculos emocionais, remetem ao universo da vida privada e das relações familiares, por ser esta a esfera que temos maiores oportunidades de vivenciar elos emocionais. Estas questões são na nossa cultura associadas às mulheres e implicou numa construção social de que estes aspectos desqualificam o trabalho docente por estarem articulados à feminilidade, provocando de certa forma pouca ênfase destes temas nos cursos de formação. Entretanto, os cursos de formação precisam trabalhar com as múltiplas dimensões que envolvem a docência (afetiva, emocional, cognitiva, lúdica, etc), embasados na compreensão de que tais dimensões não pertencem a um gênero, pois, envolvem o relacionamento entre professores/as e alunos/as.

Carvalho (1999b) afirma que a docência por ser uma atividade relacional, não se restringe apenas a transmissão de conteúdos, exige interação com as pessoas, mais especificamente com crianças, envolvendo neste processo afetividade, sentimentos e emoções, que são dimensões que possuem vínculos sociais e culturais com a feminilidade. Estes vínculos culturais trazem 
implicações ao trabalho docente, pois hierarquicamente são secundarizados pelos discursos oficiais, que valorizam a competência técnica, a eficiência e a competitividade no ensino. No entanto, não devemos esquecer que professores/as, crianças, estão imbricados pelas inúmeras dimensões da vida social (família, escola, vida doméstica, vida profissional) que influenciam as suas relações, lhes constituindo, produzindo modos de relações e práticas muito complexas que estão relacionadas também às construções sociais e históricas de homens e mulheres.

As crianças não produzem seus discursos no abstrato, mas dentro de um contexto em que a vida privada, as instituições escolares estão repletas de valores e práticas em que as construções sociais, culturais e históricas dos gêneros permeiam tais relações. O que as crianças suscitam, é que os elementos que foram atribuídos à feminilidade podem construir uma outra cultura escolar, podem produzir outros efeitos discursivos sobre as relações afetivas no exercício da docência, ou seja, novos significados sociais que valorizem as dimensões emocionais do trabalho docente, sem condicioná-los como um atributo feminino.

Bakhtin (2003), ao reforçar o caráter ativo dos sujeitos na emissão e recepção dos diálogos, nos lembra que o ser humano é um sujeito que fala e que ao se exprimir mostra todo o seu potencial ativo. As crianças são participantes ativos da história, das relações sociais, da sua cultura se constituem e se produzem num processo relacional, em que os valores, as ideologias, os padrões e crenças são veiculados nos diversos espaços sociais, dando forma e sentidos às suas experiências. Por isso a importância e o valor das crianças serem ouvidas, para conhecermos como concebem a profissão e os gêneros no trabalho docente, bem como, os tipos de relações que são desenvolvidas nos múltiplos espaços de circulação desses sujeitos infantis.

\section{Conclusões}

As crianças deixam claro o que gostam de fazer no espaço escolar, suas preferências, suas críticas ao trabalho docente, ou seja, as crianças se posicionam e sabem muito bem sobre o comportamento que professores/as esperam delas e definem muito claramente o que esperam de seus/as professores/as.

No trabalho com crianças o envolvimento afetivo deve ser visto como algo que por ser parte da dimensão humana, está presente neste processo, pois, a relação com as crianças envolve relações emocionais, pelo contato direto que se tem com estes sujeitos e pela própria infância, que para muitas crianças está marcada por relações que envolvem vínculos pessoais.

Em seus discursos aspectos como a afetividade, a atenção, a brincadeira, a paciência em ensinar, não são vistos como próprios da mulher. Elas percebem estes aspectos mais presentes nas professoras e justificam pelo fato de serem mulheres. No entanto, elas não afirmam que estes aspectos são de exclusividade de um sexo, elas afirmam que deveriam fazer parte da docência.

Os discursos das crianças sobre o bom ou a boa profissional, possuem imbricações com os ideais de feminilidade, com as prescrições sociais para o sexo feminino; um modelo de docência centrado nos aspectos extra-cognitivos do trabalho docente, que foram e ainda o são considerados como femininos. Talvez uma maneira do trabalho fluir melhor, seria promover novos vínculos com os/as alunos/as. Aspectos como a emoção, a paciência, não podem ser vistos como atributo de um sexo, mas como parte integrante do trabalho docente, sem que hierarquicamente se privilegie estes aspectos em detrimento de tantos outros.

Este é um grande desafio para o campo da formação de professores, pois, como a prática e as relações nela construídas estão marcadas pelas identidades de gênero de cada profissional, a dimensão social, cultural e histórica dos papéis que foram construídos para cada sexo, dos significados e das prescrições sociais para homens e mulheres, devem ser trazidos para o campo da formação, para serem discutidos, avaliados, em função de que, no exercício da profissão 
entrecruzam-se dimensões que ainda são pouco analisadas, como a dimensão cultural dos masculinos e femininos que estão presentes na docência e nas interações com as crianças, já que o gênero nos constitui e permeia as nossas relações.

\section{Referências}

BAKHTIN, Mikhail. Estética da Criação Verbal. 4 ed. São Paulo: Martins fontes, 2003.

Marxismo e Filosofia da Linguagem. São Paulo: Hucitec, 2004.

BRAIT, Beth. As Vozes Bakhtinianas e o Diálogo Inconcluso. In: BARROS, Diana Luz Pessoa; FIORIN, José Luiz (Org.). Dialogismo, Polifonia, Intertextualidade: Em torno de Bakhtin. São Paulo: Edusp, 2003.

CARVALHO, Marília Pinto de. Trabalho docente e relações de gênero: Algumas indagações. In: Revista Brasileira de Educação. n. 02. mai/jun/jul/ago, 1996, p. 77-84.

. Vozes masculinas numa profissão feminina: O que tem a dizer os professores. 1998. Disponível em: 〈http://www.anped.org/reuniões/28/textos/gt03 >. Acesso em: 04 de jan de 2007. Xamã, 1999a.

No coração da sala de aula: Gênero e trabalho docente nas séries iniciais. São Paulo: - Ensino uma atividade relacional. In: Revista Brasileira de Educação. n.11. mai/jun/jul/ago, 1999b, p. 17-32.

CHAMON, Magda. Trajetória de feminização do magistério: ambigüidades e conflitos. Belo Horizonte: Autêntica, 2005.

CONNELL, Robert. Políticas da Masculinidade. In: Educação e Realidade. 20 (02), jul/dez, 1995, p. 185-206.

SARMENTO, Manuel Jacinto. Gerações e alteridade: Interrogações a partir da Sociologia da infância. In: Educação e Sociedade. v. 26, n. 91. Campinas: SP, maio/ago, 2005.

UNESCO. O perfil dos Professores Brasileiros: O que fazem, o que pensam, o que almejam. São Paulo: Moderna, 2004. 